\title{
The optimization of standard test method for chemical composition of ceramic materials by spectrophotometry
}

\author{
Jinzhang $\mathrm{Cai}^{1, \mathrm{a}}$ \\ ${ }^{1}$ Nanan Testing Institute of Quality and Metrology, Quanzhou. Fujian, China
}

\begin{abstract}
Chemical composition of ceramic materials is one of the key properties and its determination is complex and time-consuming. The melting of silicon dioxide is the most important and difficult step for its determination. This paper is about optimizing the pretreatment method from the test standard, QB/T 2578-2002 < Standard test method for chemical composition of ceramic materials by spectrophotometry $>$. It is not convenient to use mixed flux (lithium hydroxide and boric acid) for melting ceramic materials. We replaced it by lithium metaborate and inspected the influence. After optimization, ceramic materials can be melted more completely. The test steps don't change much except CaOandthe test result is the same as before.
\end{abstract}

\section{Introduction}

Chemical composition of ceramic materials has important influence on physical and chemical properties of ceramics. Soit is important to test chemical composition of ceramic materials. Ceramic materials usually contain $\mathrm{SiO}_{2}, \mathrm{Al}_{2} \mathrm{O}_{3}, \mathrm{Fe}_{2} \mathrm{O}_{3}, \mathrm{TiO}_{2}, \mathrm{CaO}, \mathrm{MgO}$, $\mathrm{Na}_{2} \mathrm{O}, \mathrm{K}_{2} \mathrm{O}$ and so on. There are two common test methods at present, conventional chemical analytical methods and advance instrumental analytical method ${ }^{[1-3]}$.It takes more chemical reagents, more test steps and more times to complete the test by chemical analytical method. And more toxic wastes are produced. In contrast, instrumental analytical method is sample, quick and friendly to environment because of simultaneous determination of multi-element and less reagents ${ }^{[4-5]}$. The common step of both method is sample dissolution, and it is difficult to dissolve $\mathrm{SiO}_{2}$. There are two usual methods for $\mathrm{SiO}_{2}$ dissolution, alkali fusion and acidolysis. Alkali fusion is more safer and friendly to environment because acidolysis needs HF. The common agents of alkali fusion are lithium metaborate ${ }^{[6]}$, sodium carbonate $^{[7]}$ and mixed flux ${ }^{[7-8]}$. The mixed flux on QB/T 2578-2002 is lithium hydroxide and boric acid. The defect of mixed flux is heterogeneous. This paper discusses the replace of mixed flux by lithium metaborate.

\section{Experiment}

\subsection{Instruments and reagents}

Ultraviolet-visible UV-2600. Muffle furnace: SX3-10-14, Xiangtan Instrument Co., Ltd.
Reagents: lithium metaborate, mixed flux(lithium hydroxide and boric acid, 4:1), chromogenic reagents, hydrochloric acid, sulfuric acid and so on. Standard substances: standard substance of kaolin(GBW03121a), $\mathrm{SiO}_{2}$ standard solution, $\mathrm{Al}_{2} \mathrm{O}_{3}$ standard solution, $\mathrm{Fe}_{2} \mathrm{O}_{3}$ standard solution, $\mathrm{TiO}_{2}$ standard solution, $\mathrm{CaO}$ standard solution, $\mathrm{MgO}$ standard solution, and the concentration of all standard solution is $1000 \mathrm{mg} / \mathrm{L}$.

\subsection{Methods}

Pretreatment: Add 0.33g standard solution (or 1g mixed flux) and $0.05 \mathrm{~g}$ samples into platinum crucible, mix up them, and put the platinum crucible into muffle furnace at 950 degree. After 15 min's melting, take out the crucible, cool it to room temperature and put it into $1 \mathrm{~L}$ dry beaker. Add $500 \mathrm{~mL}$ soak solution into the beaker and solve samples by ultrasonic wave until samples are completely solved.

Ultraviolet-visible spectrophotometer: $\mathrm{SiO}_{2}$ by silicon molybdenum blue spectrophotometry (the wavelength is 530nm); $\quad \mathrm{Al}_{2} \mathrm{O}_{3}$ by chlorophosphonazo-I spectrophotometry (the wavelength is $580 \mathrm{~nm}$ ); $\mathrm{Fe}_{2} \mathrm{O}_{3}$ by 1,10- Phenanthroline spectrophotometry (the wavelength is $510 \mathrm{~nm}) ; \quad \mathrm{TiO}_{2}$ by diantipyrylmethane spectrophotometry (the wavelength is $420 \mathrm{~nm}$ ); $\mathrm{MgO}$ by chlorophosphonazo-Ispectrophotometry (the wavelength is $580 \mathrm{~nm}) ; \mathrm{CaO}$, GBHA spectrophotometry(the wavelength is $510 \mathrm{~nm}$ ).

\section{Result and discussion}

\subsection{Sample fusion}

Fusion by lithium metaborate: samples melted 
completely and became colorless and transparent.

Fusion by mixed flux: samples melted completely melted and became colorless and transparent. But there were some white spots.

The mixed flux is consist of lithium hydroxide and boric acid, and lithium hydroxide excesses. So themixed flux is more alkaline than lithium metaborate. According to the melt results, lithium metaborate is alkaline enough to dissolve samples and strong alkalinity may corrode platinum crucible. In addition, the heterogeneity of mixed flux may lead to insufficient reaction in local areas.

To sum up, it is better to dissolve samples by lithium metaborate.

\subsection{Determination of oxides in ceramic materials}

The alkalinity of samples dissolved by lithium metaborate is weaker than the alkalinity by mixed flux. The solution $\mathrm{pH}$ value is key to the color reactions of oxides. $\mathrm{SiO}_{2}, \mathrm{Al}_{2} \mathrm{O}_{3}, \quad \mathrm{Fe}_{2} \mathrm{O}_{3}$ and $\mathrm{TiO}_{2}$ need acidic condition to take color reactions. The replace will not affect the color reactions because of weaker alkalinity of lithium metaborate. So the test process doesn't change. Their color reactions were normal and the linearity of the standard curves is quite well. See Figure 1-8.

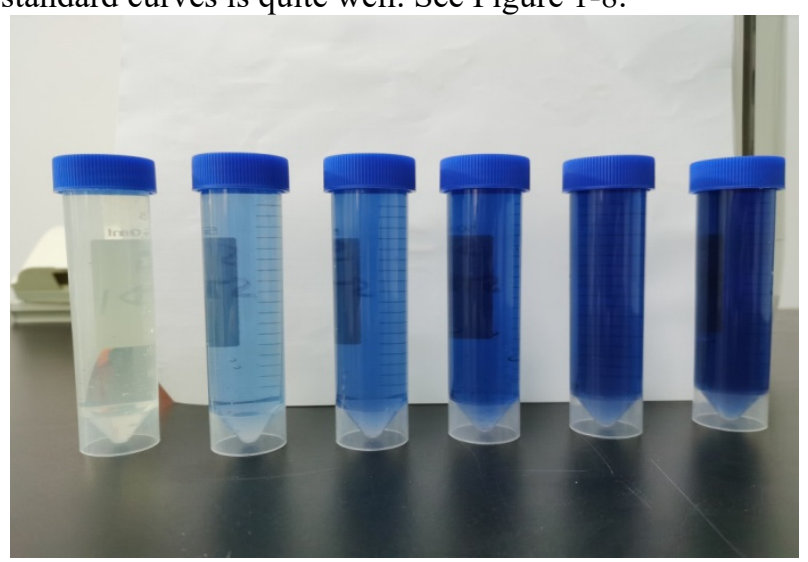

Figure 1.Color reaction of $\mathrm{SiO}_{2}$

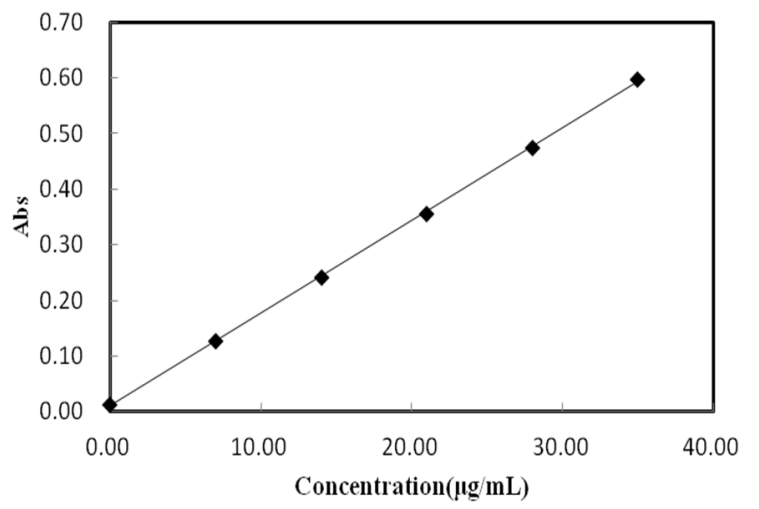

Figure 2. The standard curve of $\mathrm{SiO}_{2}$

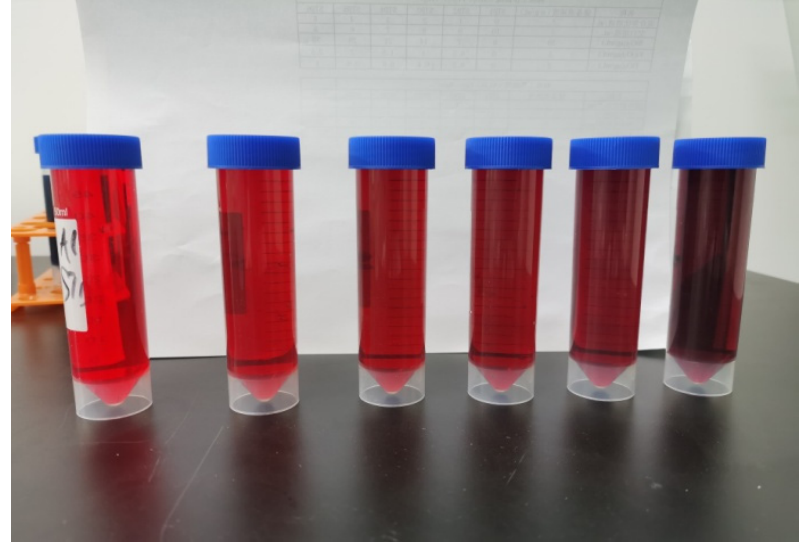

Figure 3.Color reaction of $\mathrm{Al}_{2} \mathrm{O}_{3}$

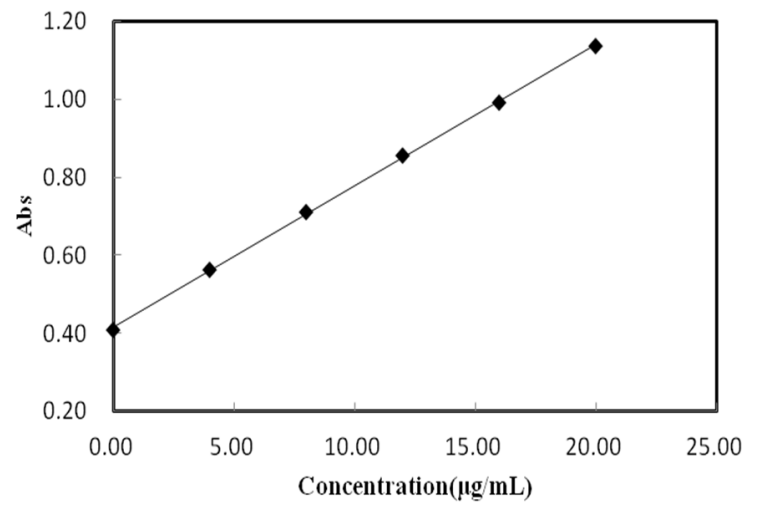

Figure 4. The standard curve of $\mathrm{Al}_{2} \mathrm{O}_{3}$

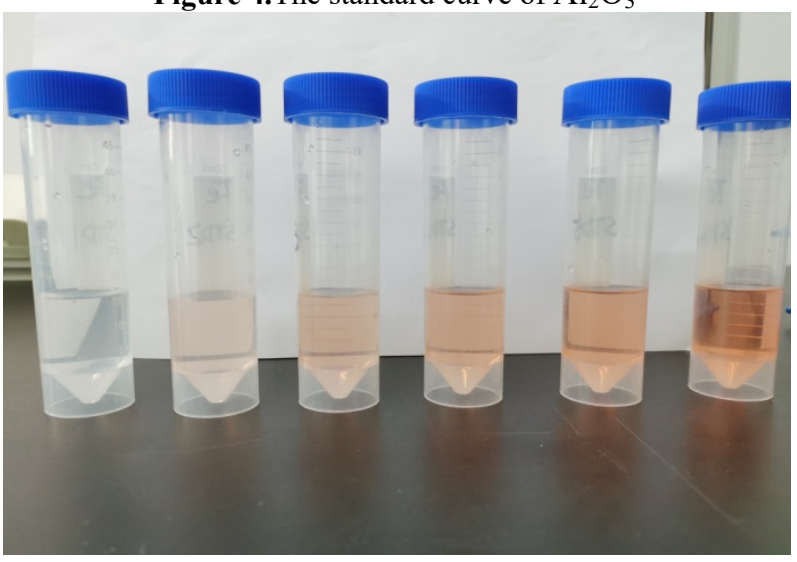

Figure 5. Color reaction of $\mathrm{Fe}_{2} \mathrm{O}_{3}$



Figure 6.The standard curve of $\mathrm{Fe}_{2} \mathrm{O}_{3}$ 


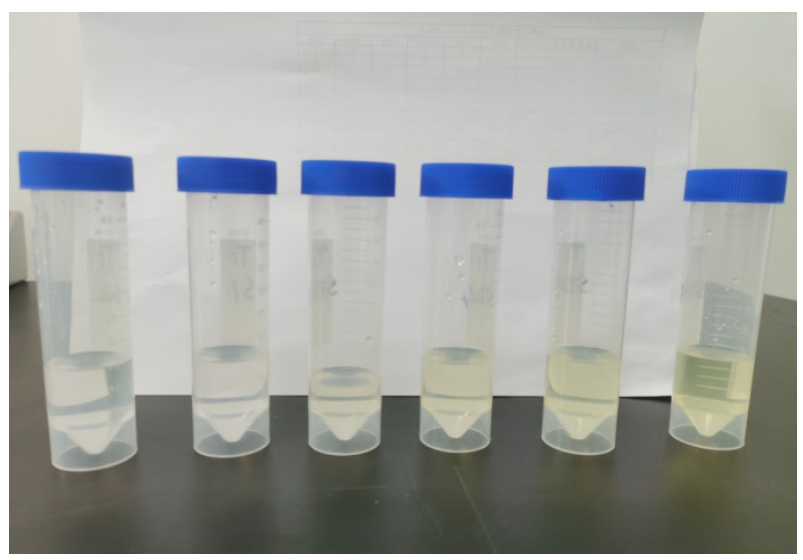

Figure 7. Color reaction of $\mathrm{TiO}_{2}$

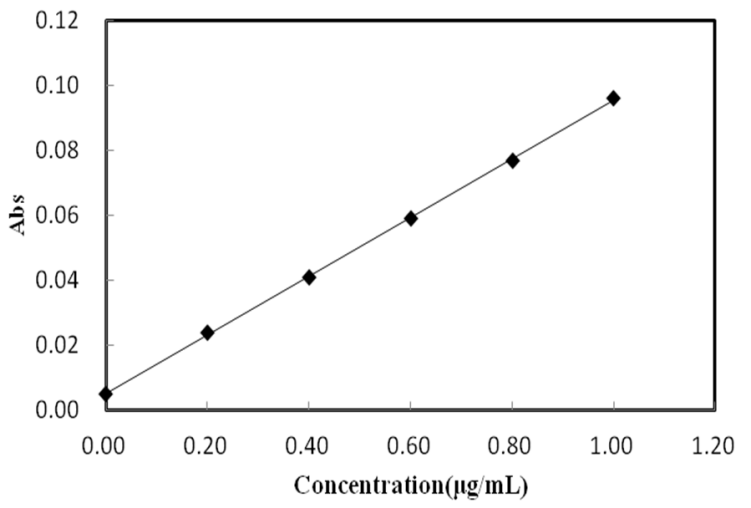

Figure 8. The standard curve of $\mathrm{TiO}_{2}$

The standard doesn't set a $\mathrm{pH}$ range for $\mathrm{MgO}$ 's color reaction. We just did the test as the standard required. We found the color reaction is normal and the linearity of the standard curve is good. See Figure 9-10.
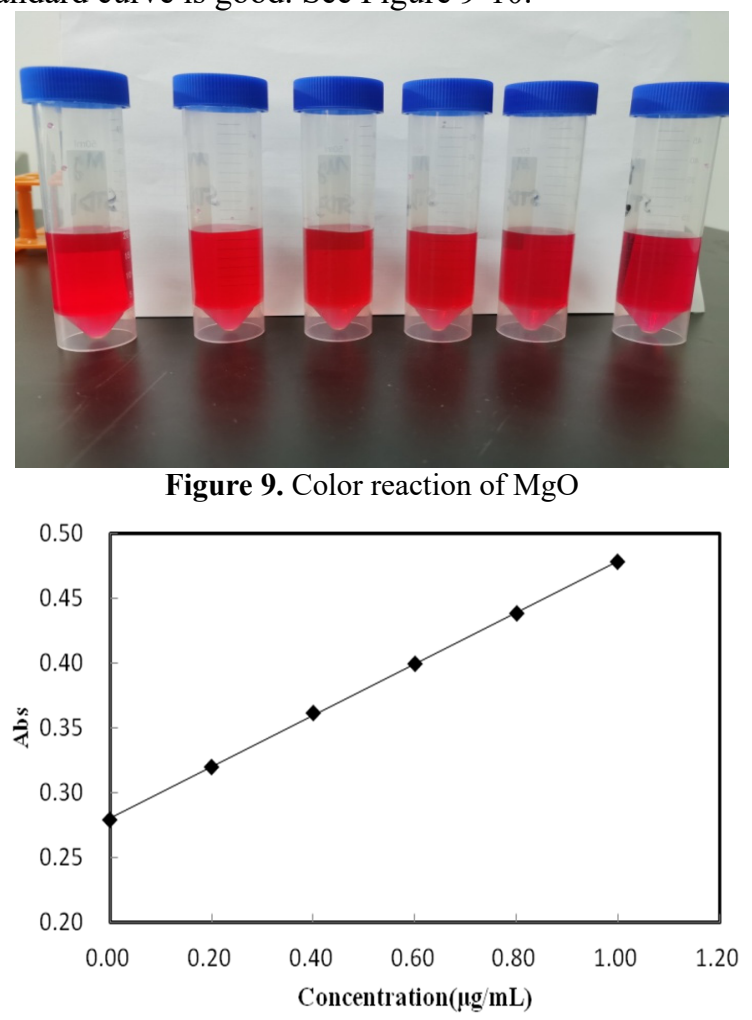

Figure 10. The standard curve of $\mathrm{MgO}$

The color reaction of $\mathrm{CaO}$ occurs at $\mathrm{NaOH}$ solution of above $0.1 \mathrm{~mol} / \mathrm{L}$. If we don't adjust $\mathrm{pH}$ of sample solutions and standard solutions, the tangerine color will occur after adding $\mathrm{Ca}$ color developing agen. This is caused by the amount of $\mathrm{NaOH}$ is not enough to neutralize $\mathrm{HCl}$. As a result, we must add proper amount of $\mathrm{LiOH}$ to adjust the $\mathrm{pH}$ of solutions. After adding $\mathrm{LiOH}$ the tangerinecolor occurs and the linearity of the standard curve is good. See Figure 2.
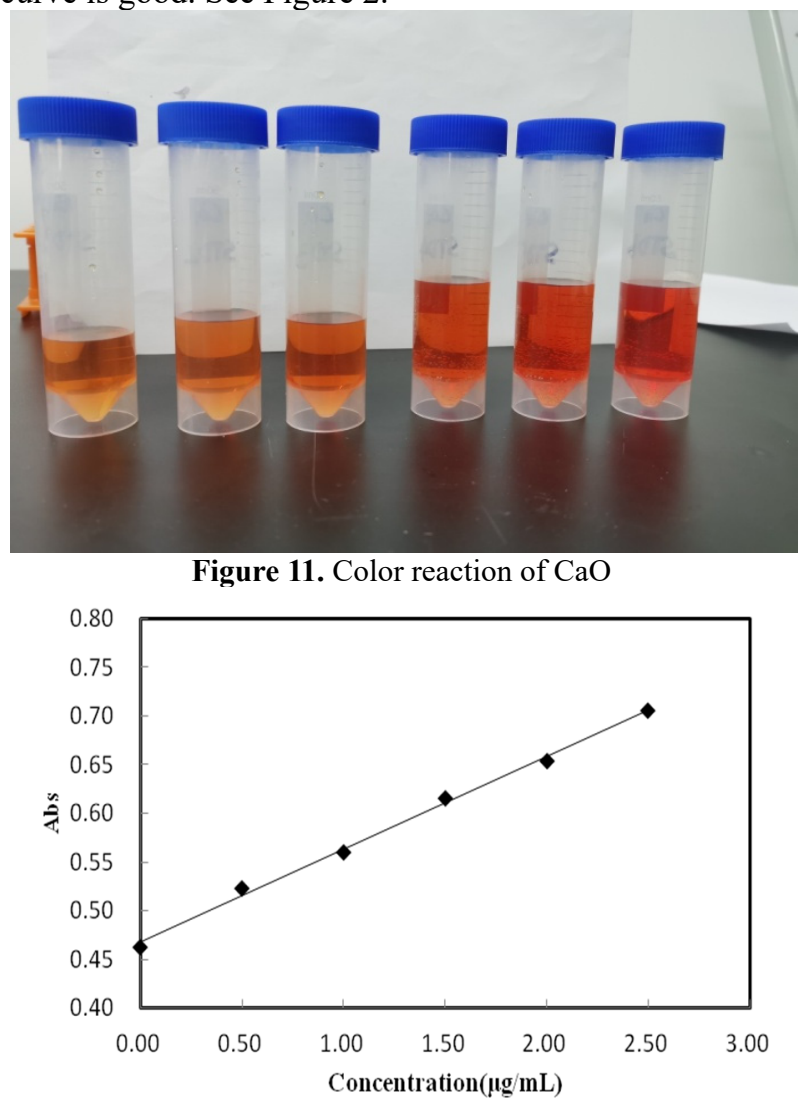

Figure12. The standard curve of $\mathrm{CaO}$

The test results of the oxides in the kaolin(GBW03121a) are as follows.

Table 1.The parallel tolerance

\begin{tabular}{|c|c|c|c|c|}
\hline & \multicolumn{2}{|c|}{ Test values } & $\begin{array}{c}\text { Parallel } \\
\text { tolerance }\end{array}$ & $\begin{array}{c}\text { Parallel } \\
\text { tolerance } \\
\text { limit }\end{array}$ \\
\hline $\mathrm{SiO}_{2}$ & $43.18 \%$ & $43.06 \%$ & $0.12 \%$ & $0.30 \%$ \\
\hline $\mathrm{Fe}_{2} \mathrm{O}_{3}$ & $1.55 \%$ & $1.41 \%$ & $0.14 \%$ & $0.15 \%$ \\
\hline $\mathrm{TiO}_{2}$ & $0.32 \%$ & $0.30 \%$ & $0.02 \%$ & $0.05 \%$ \\
\hline $\mathrm{Al}_{2} \mathrm{O}_{3}$ & $34.20 \%$ & $34.23 \%$ & $0.03 \%$ & $0.40 \%$ \\
\hline $\mathrm{MgO}$ & $0.061 \%$ & $0.071 \%$ & $0.01 \%$ & $0.05 \%$ \\
\hline $\mathrm{CaO}$ & N.D. & N.D. & $/$ & $/$ \\
\hline
\end{tabular}


Table 2. The test errors compared to standard values

\begin{tabular}{|c|c|c|}
\hline & Test Values & $\begin{array}{c}\text { Standard } \\
\text { Values }\end{array}$ \\
\hline $\mathrm{SiO}_{2}$ & $43.12 \%$ & $43.41 \%$ \\
\hline $\mathrm{Fe}_{2} \mathrm{O}_{3}$ & $1.48 \%$ & $1.50 \%$ \\
\hline $\mathrm{TiO}_{2}$ & $0.31 \%$ & $0.25 \%$ \\
\hline $\mathrm{Al}_{2} \mathrm{O}_{3}$ & $34.22 \%$ & $34.70 \%$ \\
\hline $\mathrm{MgO}$ & $0.066 \%$ & $0.069 \%$ \\
\hline $\mathrm{CaO}$ & N.D. & $0.038 \%$ \\
\hline
\end{tabular}

As the tables show, the Parallel tolerances of all oxides are within the limits and test values are all close to standard values. Detection limit for $\mathrm{CaO}$ is $0.1 \%$, so the result is N.D. So it is OK to replace mixed flux by lithium metaborate.

\section{Conclusion}

In conclusion, it is better to use lithium metaborate as flux than mixed flux and the replacing can bring several benefits.

Firstly, it becomes more easier by omitting the mixing step. The heterogeneity of mixed flux can be avoided, then the inadequacy of melting reaction and corrosion to crucible will not happen. Secondly, the replacing does not bring many changes. The testing steps almost keep the same except $\mathrm{CaO}$. The only change is adding $\mathrm{pH}$ adjust for determination of $\mathrm{CaO}$ in ceramic materials. Finally, the accuracy and stability of testing do not change. The Parallel tolerances of all oxides are within the limits and test values are all close to standard values.

\section{References}

1. Pan, Y.L. (2002) Contrast and selection of analysis methods of $\mathrm{SiO}_{2}$. China Ceramics, 38: 33-35

2. Zheng, P.F. (2013) Contrast of analysis methods of $\mathrm{SiO}_{2}$ in ceramic materials. Ceramics, 10: 11-13

3. Shi, X.T., Yi H.Y., Wang, H.J., Huang, Z. G., Lei, L.W., Xiao, H., Determination of titanium dioxide in raw materials of ceramics by microwave digestion spectrophotometry. Chemical Analysis and Meterage, 26:47-50

4. Feng, L., Chen, Z.W. (2008) Research progress of methods to the analysis of ceramic raw materials. China Ceramics, 44: 14-16

5. Lin, S. (2012) The analysis on the applicability of several method for chemical composition of ceramic materials. Foshan Ceramics, 22: 28-31

6. GB/T 14506.31-2019 Methods for chemical analysis of silicate rocks-Part 31: Determination of 12 components including silicon dioxide etc.-Lithium metaborate fusion-inductively coupled plasma atomic emission spectrometry

7. GB/T 4734-1996 Methods of chemical analysis for ceramic materials and articles

8. QB/T 2578-2002 Standard test method for chemical composition of ceramic materials by spectrophotometry 